\title{
Disease Severity, Health Beliefs, and Medication Adherence among HIV Patients in a Tertiary Hospital Abuja, Nigeria
}

\author{
Olugbenga Aremu, Ijaodola ${ }^{1 *}$, Adedayo Adeyemi ${ }^{2}$, Cyril Egbo $^{3}$, Ademidun Oluwatoyin \\ Adedeji $^{4}$ \\ ${ }^{1}$ Prevention of Mother to Child Transmission branch, National AID and STIs Control \\ Program, Federal Ministry of Health, Nigeria \\ ${ }^{2}$ Monitoring and Evaluation Expert, Center for Infectious Research and Evaluation Abuja, \\ Nigeria \\ ${ }^{3}$ Department of Community Medicine, University of Benin, Benin-city, Nigeria \\ ${ }^{4}$ Department of Nursing Service, University of Medical Sciences Teaching Hospital Ondo, \\ Nigeria
}

\begin{abstract}
Anti-retroviral therapy (ART) has decreased the mortality and morbidity of HIV/AIDS. Several medicines are prescribed for disease management; however, adherence to long-term therapy remains poor. Disease severity and health beliefs about medications ultimately influence adherence to treatment. There is a paucity of data with regard to disease severity, health beliefs and medication adherence among HIV patients. The purpose of the study was to investigate the relationship between disease severity, health beliefs, and medication adherence among HIV patients. A cross-sectional descriptive survey was used. Data were collected among $400 \mathrm{HIV}$-infected patients on ARV who received pretreatment and ongoing adherence counseling and education since 2010 using a selfadministered questionnaire. The data were analyzed using Statistical Package for Social Sciences (SPSS). Findings showed that $68.3 \%$ believed that there is a great chance of developing AIDS-related complications if ARV is not taken as directed, while 3.3\% do not agree that taking HIV medication as prescribed can prolong life. The majority (95.5\%) reported three is no difficulty with the prescribed regimen while $96.7 \%$ felt weird like a 'zombie' on medication and $95 \%$ agreed with the fact that ART medication can prevent the development of AIDS. Medication adherence is a complex, multifaceted issue and patient beliefs about medications contribute significantly, although to adherence. It is important to assess health beliefs for individual patients. When individual beliefs appear likely to undermine adherence, it may be useful to undertake educational interventions to try to modify them.
\end{abstract}

Keywords: Disease severity, Health beliefs, HIV-infected patients, Medication adherence.

\section{Introduction}

HIV is a mounting health disparity and public health crisis. Advances in the medical treatment of HIV have led to significantly longer life expectancies for those living with HIV [1]. Studies have shown that medicationtaking behaviors are related to the severity of the disease [2, 3, 4]. Patients with different symptoms of disease or patients with different diseases (fatal or mild chronic) may have different responses to treatment.

Disease severity is also shown to influence health beliefs and is typically treated as a cue to action in most studies using HBM [5, 6]. Most of the medication adherence literature focuses on illnesses that tend to be chronic in nature and not immediately life-threatening, such as hypertension, heart disease, and diabetes 
mellitus [7]. HIV infection is a more serious illness, although recently, some medications have been developed to prolong and increase the quality of life. Another aspect of HIV infection is that symptoms can vary greatly in frequency and severity among HIV patients. In the early stages of the disease, there may be no symptoms experienced by the patient, and the consequences of terminating treatment are delayed [8]. Hence, some patients in this stage may be more sensitive to the side effects of the medication despite its benefits and may not feel any discomfort soon after discontinuing their medications.

Patients make critical decisions that affect the therapeutic outcome of their disease [9]. In this sense, patients share power with providers in the consumption process. Patients' beliefs about disease and medications may be crucial to their intentional adherence behaviors and may be very different than providers [9]. Thus, an apparently irrational act of non-adherence from the physician's or pharmacist's point of view may be a very rational action when seen from the patient's perspective. However, very little is known about how disease severity affects perceptions of health status, perceived benefits, and perceived barriers of treatment and further affects decision-making regarding medication adherence among HIV/AIDS patients. Symptoms can vary greatly in frequency and severity among HIV patients. Thus, there is likely to be considerable variability among HIV patients' perceptions of disease severity and progression, perceived benefits and costs of medication adherence, and other factors.

Consequently, providing generalized information about HIV may not improve a patient's adherence behaviors. The effectiveness of an education intervention will be enhanced if the information targets the key perceptions of that patient. The effectiveness of adherence-gaining strategies may depend upon the extent to which they match patients' beliefs about health and medications. Therefore, knowing whether patients' beliefs about their health and medications change in a predictable way as their disease progresses may lead to the more effective design of drug therapy regimens and counseling approaches.

This study evaluated the relationship of disease severity, health beliefs, and medication adherence among HIV patients in an HIV treatment center in Nigeria.

\section{Methods}

\section{Design}

The study adopted a descriptive crosssectional design to the relationship of disease severity, health beliefs, and medication adherence among HIV patients in an HIV treatment center in Nigeria.

\section{Description of the Site}

This study was carried out in District Hospital, Wuse Abuja, Nigeria, a secondary public health care facility that offers comprehensive HIV care services, including anti-retroviral therapy (ART). It has a 120-bed capacity and serves the people living in the Wuse district and its environs. In this hospital, HIV-positive clients identified at the HIV counselling and testing service points are enrolled into a Pre-ART register for follow-up, and only those who meet the eligibility criteria for starting anti-retroviral therapy based on the Nigeria national ART guideline are commenced on treatment. Anti-retroviral drugs and a number of drugs for the treatment of opportunistic infections and other related services are fully funded by the Federal Government of Nigeria with the support of President's Emergency Plan for AIDS Relief (PEPFAR) through US Agency for International Development (USAID) and are provided at no-cost to the patients.

\section{Sampling and Sampling Technique}

The study population included a cohort of 400 HIV infected comprised of antiretroviraltherapy-naïve adults (aged 18 years or older) patients who were enrolled and commenced 
anti-retroviral therapy (ART) from January 1, 2010 till September, 2020 at Wuse District Hospital Abuja, FCT Nigeria; and received the medication adherence intervention. The sample size was determined using Cochran's formula $n$ $=\mathrm{Z}^{2} \mathrm{pq} / \mathrm{d}^{2}$. Based on a previous prevalence of $30 \%$ and $40 \%$ buffer for incomplete questionnaires and other unexpected circumstances, the calculated sample size was 400. The study employed simple random sampling. Clinic attendance for their fourweekly refill of ARVs where patients received regular health education sessions and adherence counselling support which is part of the routine care that the HIV/ART clinic provided; was monitored, and it was categorized into regular and non-regular attendance. Patients who had regular attendance were selected for the study will be selected.

\section{Data Collection}

Data were collected with the use of a studyspecific semi-structured 17-item questionnaire to assess self-reported adherence, reasons for missing doses, which was administered to the study participants at medications refill visits in the pharmacy. For illiterate participants, the questionnaire was administered under the supervision of the research assistants. The study participants were educated about the study, its benefits, and their informed consent obtained before the commencement of the study. The participants were assured of the confidentiality of the information.

The study instrument was field-tested among HIV-positive patients who refilled their antiretroviral drugs at the ART Pharmacy in the HIV/AIDS Treatment Centre, General Hospital Maitama, Abuja.

\section{Validity and Reliability}

The face and content validity of the instrument was ensured by versatile independent researchers in related fields. The study instrument was field-tested among HIVpositive patients who refilled their anti- retroviral drugs at the ART Pharmacy in the HIV/AIDS Treatment Centre, General Hospital Maitama, Abuja. The feedback was used to review the questionnaire by the researcher and expert colleagues for content validity, and reliability tested using the test-re-test technique. The characteristics of the hospital and participants used in the field testing were similar to the study site and sample.

\section{Procedure for Data Collection/Ethical Approval}

The study participants were educated about the study, its benefits, and their informed consent obtained before the commencement of the study. The participants were assured of the confidentiality of the information. For illiterate participants, the questionnaire was administered under the supervision of the research assistants. The feedback was used to review the questionnaire by the researcher and expert colleagues for content validity, and reliability tested using the test-re-test technique. The characteristics of the hospital and participants used in the field testing were similar to the study site and sample.

Patients who met the inclusion criteria were informed by the physician, or the clinic pharmacist, about the purpose and nature of the study. Verbal information regarding the study and the patient's right to refusal were provided. Patients who agreed to participate were given the written questionnaire on which their pharmacist or physician had indicated the patient's disease stage.

The subjects were allowed to complete the survey in the clinic. The questionnaire was returned to investigators at for data analysis. Hence, the physician would not see the patient's responses, and the investigators would not know the identity of the respondent, thereby ensuring anonymity.

An approval letter from the HIVAIDS division, FMOH, was obtained for the study procedures and data collection instruments. Ethical approvals were received from the FCT 
Ethical committee, where the study center falls under, and final approval was received from the authority of the General Hospital Wuse.

\section{Data Analysis}

Statistical Package for Social Sciences (SPSS) was used for data analysis. The data file contained seventy- cases that represented the usable questionnaires. The data file was meticulously checked to correct errors from data entry. Frequencies were then obtained for all study variables to double-check and clean data. Descriptive statistics such as frequency distribution, simple percentages were used. Self-reported adherence was calculated as the mean scores of patients' adherence to the specific timing for taking the medications (medication schedule) and the number of prescribed doses of medications missed. Chi-
Square statistics were used to test the association of adherence with occupation and education. All reported P-values were 2-sided, and $\mathrm{P}<0.05$ was used to determine statistical significance, except where otherwise indicated.

\section{Results}

\section{Socio-demographic Characteristics of Patients}

The mean age of the 400 patients on antiretroviral treatment during the study was 38.9 years $(95 \% \mathrm{CI}, 33.9 \pm 4.3)$; and the majority $(48.0 \%)$ were between the ages of 31 to 40 years; $36.7 \%$ females; $44.7 \%$ were in a nuclear family setting; $53.3 \%$ had secondary education, and $52.7 \%$ were self-employed. Details of the socio-demographic characteristics were presented in Table 1.

Table 1. Distribution of the Socio-Demographic Characteristics of the Study Participants

\begin{tabular}{|c|c|c|c|c|}
\hline $\mathbf{S} / \mathbf{N}$ & Variables & Characteristics & Frequency & Percentage $(\%)$ \\
\hline \multirow[t]{2}{*}{1} & \multirow[t]{2}{*}{ Gender } & Male & 253 & 63.3 \\
\hline & & Female & 147 & 36.7 \\
\hline \multirow[t]{3}{*}{2} & \multirow[t]{3}{*}{ Age } & $20-30$ & 65 & 16.3 \\
\hline & & $31-40$ & 192 & 48.0 \\
\hline & & $>40$ & 143 & 35.7 \\
\hline \multirow[t]{5}{*}{3.} & \multirow[t]{5}{*}{ Educational Level } & Illiterate & 57 & 14.3 \\
\hline & & Islamic School & 11 & 2.7 \\
\hline & & Primary & 67 & 16.7 \\
\hline & & Secondary & 213 & 53.3 \\
\hline & & University and above & 47 & 11.7 \\
\hline \multirow[t]{3}{*}{4} & \multirow[t]{3}{*}{ Occupation } & Unemployed & 100 & 25.0 \\
\hline & & Self-Employed & 211 & 52.7 \\
\hline & & Employed & 89 & 22.3 \\
\hline \multirow[t]{4}{*}{5} & \multirow[t]{4}{*}{ Family Type } & Living alone & 133 & 33.3 \\
\hline & & Nuclear & 179 & 44.7 \\
\hline & & Extended & 57 & 14.3 \\
\hline & & Unknown & 31 & 7.7 \\
\hline \multirow[t]{2}{*}{6} & \multirow[t]{2}{*}{ Locality } & Rural & 135 & 33.7 \\
\hline & & Urban & 265 & 66.3 \\
\hline \multirow[t]{3}{*}{7} & \multirow[t]{3}{*}{ Distance from Clinic $(\mathrm{Km})$} & $50-200$ & 7 & 1.7 \\
\hline & & $200-400$ & 23 & 5.7 \\
\hline & & $>400$ & 370 & 92.6 \\
\hline
\end{tabular}




\section{Exposure to medication and other history}

Most of the respondent reported good regular clinic follow-up (50\%) while a majority of the respondent believes condition to be normal $(63.3 \%)$. Only $10.0 \%$ of the respondents have been on ART for more than 4 years. The majority of the respondent did not perceive any difficulty in the regimen (95\%). Most of the respondents only see the physician every 3 months $(63.3 \%)$ for medication. Only $33.3 \%$ of the respondent declared taken other health products in addition to the prescribed medication in the past months. It was reported that half of them drink alcohol (Table 2).

Table 2. Frequency Distribution on Exposure to Medications History Reported by the Respondents $(\mathrm{N}=400)$

\begin{tabular}{|c|c|c|c|c|}
\hline $\mathbf{S} / \mathbf{N}$ & \multicolumn{2}{|l|}{ Characteristics } & Frequency $(\mathbf{N})$ & Percentage $(\%)$ \\
\hline \multirow{2}{*}{1} & \multirow[t]{2}{*}{ Clinic Follow-up } & Regular & 200 & 50 \\
\hline & & Irregular & 200 & 50 \\
\hline \multirow[t]{3}{*}{2} & \multirow[t]{3}{*}{ Patient perception of well-being } & Sick & 36 & 9.0 \\
\hline & & Stable & 107 & 26.7 \\
\hline & & Normal & 253 & 63.3 \\
\hline \multirow[t]{2}{*}{3} & \multirow[t]{2}{*}{ History of previous AIDS-defining illness } & Yes & 356 & 89 \\
\hline & & No & 44 & 11 \\
\hline \multirow[t]{3}{*}{4} & \multirow[t]{3}{*}{ Ailments presently suffering } & AIDS & 132 & 33 \\
\hline & & Well (none) & 187 & 46.7 \\
\hline & & Ill not AIDS & 81 & 20.3 \\
\hline \multirow[t]{3}{*}{5} & \multirow[t]{3}{*}{ Time since Diagnosis (years) } & $<1$ & 67 & 16.7 \\
\hline & & $1-4$ & 267 & 66.7 \\
\hline & & $5+$ & 66 & 16.6 \\
\hline \multirow[t]{3}{*}{6} & \multirow[t]{3}{*}{ Time since starting ART (years) } & $<1$ & 53 & 13.3 \\
\hline & & $1-4$ & 307 & 76.7 \\
\hline & & $5+$ & 40 & 10 \\
\hline \multirow[t]{2}{*}{7} & \multirow[t]{2}{*}{ Number of tablets/days } & less than 4 & 387 & 96.7 \\
\hline & & $4-7$ & 13 & 3.3 \\
\hline \multirow[t]{2}{*}{8} & \multirow[t]{2}{*}{ Time Restriction } & Yes & 353 & 88.3 \\
\hline & & No & 47 & 11.7 \\
\hline \multirow[t]{2}{*}{9} & \multirow[t]{2}{*}{ Perceived difficulty of regimen } & Simple & 380 & 95 \\
\hline & & Moderate & 20 & 5 \\
\hline \multirow[t]{4}{*}{10} & \multirow{4}{*}{$\begin{array}{l}\text { How often do you visit or contact your } \\
\text { physician? }\end{array}$} & Once a month & 13 & 3.3 \\
\hline & & Once (2 months) & 67 & 16.7 \\
\hline & & Once (3 months) & 253 & 63.3 \\
\hline & & Then 3 months & 67 & 16.7 \\
\hline \multirow[t]{2}{*}{11} & \multirow{2}{*}{$\begin{array}{l}\text { Do you find it difficult to get your } \\
\text { prescription medications? }\end{array}$} & Yes & 20 & 5 \\
\hline & & No & 380 & 95 \\
\hline \multirow[t]{2}{*}{12} & \multirow{2}{*}{$\begin{array}{l}\text { Did you use any of these or other health } \\
\text { products in the past } 6 \text { months? }\end{array}$} & Yes & 133 & 33.3 \\
\hline & & No & 267 & 66.7 \\
\hline \multirow[t]{2}{*}{13.} & \multirow{2}{*}{$\begin{array}{l}\text { At the present time, do you smoke } \\
\text { (cigarettes/cigars/pipe/chewing tobacco? }\end{array}$} & Yes & 133 & 33.3 \\
\hline & & No & 267 & 66.7 \\
\hline \multirow[t]{2}{*}{14.} & \multirow{2}{*}{$\begin{array}{l}\text { At the present time, do you drink } \\
\text { (consume alcohol)? }\end{array}$} & Yes & 200 & 50 \\
\hline & & No & 200 & 50 \\
\hline
\end{tabular}


Level of Remembrance and Chances of Progression of Disease

The highest percentage of the respondents $(61.7 \%)$ rarely remember to take their medication. The majority of the respondents have a high chance $(68.3 \%)$ of disease progression (Table 3).

Table 3. Frequency Table Showing the Level of Remembrance to Medication, Chances of Progression of Diseases

\begin{tabular}{|l|l|l|l|}
\hline S/N & Characteristics & Frequency(N) & Percentage (\%) \\
\hline \multicolumn{2}{|l|}{ Level of Remembrance to Medication } \\
\hline 1 & Never/Rarely & 247 & 61.7 \\
\hline 2 & Once in a while & 93 & 23.3 \\
\hline 3 & Sometimes & 27 & 6.7 \\
\hline 4 & Usually, & 13 & 3.3 \\
\hline 5 & All the time & 17 & 4.3 \\
\hline Chances of Progression of Diseases & \multicolumn{2}{l|}{} \\
\hline 1 & very low & 40 & 10.0 \\
\hline 2 & low intermediate & 27 & 6.7 \\
\hline 3 & High & 273 & 68.3 \\
\hline 4 & very high & 60 & 15.0 \\
\hline
\end{tabular}

\section{Responses to Medication}

All the participants reported being counseled on the benefits of ART and medication adherence, including how to use their medications before commencing ART. Of the 400 participants, $380 \quad(95.0 \%)$ reported knowing the benefits of anti-retroviral therapy, $13(3.3 \%)$ reported not knowing the benefits of ART, while 93(23.3\%) respond neutrally. On assessing the participants' knowledge of the benefits of ART, the majority of the participants, 293 (73.3 \%), who reported knowing the benefits of ART responded correctly that it causes suppression of the virus, improvement of body's immune system, prolongation life and improvement of quality of life; 93 (23.3\%) did not respond at all, while 13 (3.3\%) responded incorrectly that ART is a cure for HIV. The majority of the participants acknowledged being provided information that ARV drugs resistance could result from nonadherence to medication but dealing with side effects of HIV medication can be stressful, with $133(33.3 \%)$ reported agreeing (Table 4).

Table 4. Distribution of Respondents' Responses to Medication

\begin{tabular}{|l|l|l|l|l|}
\hline S/N & Characteristics & Disagree (f/\%) & Neutral (f/\%) & Agree (f/\%) \\
\hline 1 & $\begin{array}{l}\text { Compared to other illnesses, HIV/AIDS } \\
\text { is NOT very serious }\end{array}$ & $320 / 80.0$ & $60 / 15.0$ & $20 / 5.0$ \\
\hline 2 & $\begin{array}{l}\text { If I do NOT take my HIV medications } \\
\text { as prescribed, I will become very sick }\end{array}$ & $20 / 5.0$ & $33 / 8.3$ & $347 / 86.7$ \\
\hline 3 & $\begin{array}{l}\text { If I take my HIV medications as } \\
\text { prescribed, I will still become very sick }\end{array}$ & $293 / 73.3$ & $93 / 23.3$ & $13 / 3.3$ \\
\hline 4 & $\begin{array}{l}\text { Taking HIV medications as prescribed } \\
\text { can prolong my life. }\end{array}$ & $13 / 3.3$ & $93 / 23.3$ & $293 / 73.3$ \\
\hline 5 & $\begin{array}{l}\text { Taking HIV medications interferes a } \\
\text { great deal with my normal activities. }\end{array}$ & $93 / 23.3$ & $200 / 50.0$ & $107 / 26.7$ \\
\hline
\end{tabular}




\begin{tabular}{|l|l|l|l|l|}
\hline 7 & $\begin{array}{l}\text { Taking HIV medications exactly as } \\
\text { prescribed decreases the chances of my } \\
\text { illness getting worse }\end{array}$ & $13 / 3.3$ & $27 / 6.7$ & $360 / 90.0$ \\
\hline 8 & $\begin{array}{l}\text { HIV medications cause annoying side } \\
\text { effects }\end{array}$ & $87 / 21.7$ & $213 / 53.3$ & $300 / 25.0$ \\
\hline 9 & $\begin{array}{l}\text { Taking HIV medications or having side } \\
\text { effects from them has made me feel } \\
\text { more nervous or depressed than usual. }\end{array}$ & $87 / 21.7$ & $187 / 46.7$ & $127 / 31.7$ \\
\hline 10 & $\begin{array}{l}\text { Dealing with the side effects of HIV } \\
\text { medications is stressful }\end{array}$ & $93 / 23.3$ & $173 / 43.3$ & $133 / 33.3$ \\
\hline 11 & $\begin{array}{l}\text { The HIV medications that I'm taking } \\
\text { will improve my health (i.e., raise } \\
\text { immune system, cause weight gain, } \\
\text { etc.). }\end{array}$ & $13 / 3.3$ & $93 / 23.3$ & $293 / 73.3$ \\
\hline 13 & $\begin{array}{l}\text { It is difficult to follow doctors' } \\
\text { instructions on HIV medications }\end{array}$ & $293 / 73.3$ & $0 / 0$ & $107 / 26.7$ \\
\hline
\end{tabular}

\section{Discussion}

Medication adherence increased as patients' disease severity increased when regimen complexity was controlled. The trend was more significant between asymptomatic patients (stage A) and symptomatic patients (stage B and $\mathrm{C}$ ). Although one might expect less adherence in patients with more advanced HIV disease because of their increased medication needs and decreased level of physical functioning, this is often not the case. Patients who have experienced more disease symptoms are likely to have higher medication adherence. They may feel a higher risk of complications or have more experience in coping with the barriers of the treatment (e.g., side effects) compared to patients in the early stages of the disease. Regimen complexity was found not a significant predictor of medication adherence. However, many studies have indicated that medication adherence is strongly associated with regimen complexity $[10,11,12]$.

In this study, regimen complexity was calculated based on the number of daily doses. Complexity may actually be influenced by other issues, such as the timing of the doses. For example, having to take five medications that are all taken at the same dosing interval (e.g., three times a day) may be easier than taking one medication twice daily, along with another medication dosed three times a day and a third drug dosed four times a day. Their past disease experiences influence patients' current medication adherence. It is possible that the effect of disease severity on medication adherence is mediated by patients' perceived risk of getting worse given non-adherence (susceptibility-inaction). Greater experience in dealing with disease symptoms and medication use can lead to a higher perceived risk of complications. The perceived link between nonadherence and the development of complications may be reinforced through one's personal or vicarious experience of having developed complications when non-adherent. Counseling by health professionals on the dangers of non-adherence may also influence this perception. Conversely, patients who are in better health or have had no symptoms may have poor medication adherence because they feel less immediately susceptible to the complications of the illness (low perceived susceptibility inaction).

The advent of highly active anti-retroviral therapy (HAART) means that more HIV patients need to take multiple medications for longer periods [13], but with the introduction of 
a combination regimen, it is expected this should improve adherence. In addition, many anti-retrovirals may have adverse effects, rigorous dosage and administration requirements, be associated with numerous drug interactions [14, 15]. Since symptoms can vary greatly in frequency and severity among HIV patients [13], there is likely to be considerable variability amongst HIV patients' perceptions of disease severity and progression as well as perceived benefits. Patients' medication adherence may also be influenced by their disease experiences. However, very little is known about how disease severity affects patients' beliefs about disease and medications and patients' medication taking behaviors.

Perceived susceptibility and severity of the disease and perceived benefits and barriers of the treatment are related to similarly worded questions about the risks of non-adherence and benefits of adherence. This leads to a possible explanation that the degree to which a patient feels threatened by the aggravation of HIV infection is conditional upon whether or not they take their medications. Perceived susceptibility may be highly correlated with the perceived effectiveness (i.e., perceived benefit) of the treatment. For example, a patient who believes that his medications are highly effective is more likely to believe that he is at lower risk of complications as long as he takes his medications as prescribed. He is at higher risk if he does not take the medications as prescribed.

In addition, most patients agreed their treatment was very beneficial regardless of their disease stage. This may be due to the fact that treatments for HIV/AIDS have developed remarkably in recent years. Compared to treatments in the 1980's and the early 1990's, the new combined anti-retroviral therapy has significant improvement in treatment effectiveness [16]. The progress is so obvious that most patients appreciate the new technologies/medicines for prolonging their life and preventing disease. On the other hand, despite the development in HIV/AIDS medications, side effects of anti-retroviral are still relatively common and difficult to avoid due to the limited numbers and classes of antiretroviral. All anti-retroviral agents are associated with considerable toxicities [17]. Also, the combined anti-retroviral therapy increases regimen complexity, which may be more inconvenient for patients. Patients without severe disease-related symptoms may perceive high treatment barriers because the side effects of their medications appear relatively intolerable compared to their disease experience, whereas patients with advanced disease may perceive high treatment barriers because they actually experience a greater incidence of adverse effects. As the course of HIV disease progresses, and treatment alternatives become limited, it is more likely that remaining treatment options will have overlapping adverse effect profiles:[17]. However, patients with AIDS or ARC may also perceive the side effects of medications and/or other inconveniences caused by the treatment as more tolerable compared to the advancement of their disease. Although the responses to individual barrier items were mixed, the summated barriers scale indicated that the overall perception of barriers was relatively high.

Disease severity was associated with perceived susceptibility. That means HIV patients who have had severe complications perceive themselves to be at greater risk of getting worse when not adherent as compared to patients who have never experienced complications. On the contrary, there was no significant difference in perceived susceptibility-action among HIV patients in different disease stages.

Inconsistent with the literature, self-reported medication adherence was quite high in our study patients: $100 \%$ had perfect adherence during the past one day. Results also revealed that some patients $(6.7 \%)$ purposefully stopped 
taking their HIV medications and the most common reason for intentional non-adherence was the intolerable side effects of the medication.

\section{Conclusion}

The illness experiences of persons with HIV influence how they rate their chances of developing complications if they are not adherent to their medications. This further influences their medication adherence behaviors. Patients who have experienced AIDS-related complications have higher perceptions of their susceptibility to further complications and have higher medication adherence rates than those earlier in the disease process. Difficulties in following doctors' instructions also affect HIV patients' medication adherence. The greater the perceived difficulty in following doctors' instructions, the lower the medication adherence rate. Patients' medication-taking behaviors can be improved, and the optimal treatment outcomes could be achieved by targeting issues specific to the individual patient, enhancing the relationship between patients and health care providers, and helping patients understand the negative consequences of poor adherence.

\section{References}

[1] Sayegh P, Thaler NS, Arentoft A, Kuhn TP, Schonfeld D, Castellon SA, Durvasula RS, Myers $\mathrm{HF}$, Hinkin $\mathrm{CH}$. Medication adherence in HIVpositive African Americans: The roles of age, health beliefs, and sensation seeking. Cogent psychology. 2016 Dec 31;3(1):1137207.

[2] Graham N, Jacobson LP, and Kuo V. Access to Therapy in The Multicenter AIDS Cohort Study, 1989-1992. J Clin Epidemiol. 1994; 47(9): 1003-12.

[3] Smith, S. A Longitudinal Study of Access and Drug Utilization in a Cohort with HIV Disease. Doctoral Dissertation, University of Michigan, 1996.
Intensive adherence counseling should be provided to all patients before the initiation of anti-retroviral therapy. Health care providers must identify possible barriers to adherence at the earliest and provide appropriate solutions.

\section{Authors Contribution}

O.A. and A.A. contributed to the conception and design of this study, O.A and C.E. performed the statistical analysis, O.A and A.O. drafted the manuscript, O.A, C.E and A.O. critically reviewed the manuscript while A.A. supervised the whole study process. All the authors read and approved the final manuscript.

\section{Acknowledgements}

The author deeply appreciates the management of Wuse District Hospital Abuja, FCT Nigeria.

\section{Funding}

The author(s) received no financial support for the research and/or publication of this article.

\section{Declaration of Conflicting Interests}

The author(s) declared no potential conflicts of interest with respect to the research, authorship, and/or publication of this article.

[4] Spilker B. Methods of Assessing and Improving Patient Compliance in Clinical Trials. IRB. A Review of Human Subjects Research, 1992; 14(3): 16.

[5] Geletko SM, Ballard CR, Mathews WC. Health Beliefs and Discontinuation of Zidovudine Therapy. Am J Health-Syst Pharm. 1995; 52: 505-7.

[6] Conner M, and Norman P. Comparing the Health Belief Model and The Theory of Planned Behavior in Health Screening. In: Social Psychology and Health: European Perspectives". Eds: Rutter DR and Quine L. Avebury, Brook field, VT 1994.

[7] Morse EV, Simon PM, and Coburn M. Determinants of Subject Compliance within an 
Experimental Anti-HIV Drug Protocol. Soc. Sci. Med. 1991; 32(10): 1161-7.

[8] Griffith S. A Review of The Factors Associated with Patient Compliance and The Taking of Prescribed Medicines. British Journal of General Practice 1990; 40: 114-6.

[9] Donovan JL, and Blake DR. Patient NonCompliance: Deviance or Reasoned DecisionMaking? Soc Sci Med. 1992; 34(5): 507-13.

[10] Rudd P, Tul V, and Brown K. Hypertension Continuation Adherence: Natural history and role as an indicator condition. Arch Intern Med. 1979; 139545.

[11]Eldred L, Wu A, and Chaisson RE. Adherence to Antiretroviral Therapy in HIV Disease. 4th Conference on Retroviruses and Opportunistic Infections. Washington DC. Abstract, 1997.

[12] Eraker SA, Kirscht JP, and Becker MH. Understanding and Improving Patient Compliance.
Ann Intern Med. 1984; 100:258-68.

[13] Tseng AL. Compliance Issues in the Treatment of HIV Infection. Am J Health Syst Pharm. 1998; 55:1817-24.

[14] Deeks SG, Smith M, and Holodniy M. HIV-1 Protease Inhibitors: A review for clinicians. JAMA 1997; 277: 145-53.

[15] Swindells S, and Gendelman HE. The New Non-Nucleoside Reverse Transcriptase Inhibitors. Infect Med. 1996; 13:715-9,731.

[16] Ferradini L, Jeannin A, Pinoges L, Izopet J, Odhiambo D, and Mankhambo L. Scaling up of highly active anti-retroviral therapy in a rural district of Malawi: an effectiveness assessment. The Lancet. 2006; 367(9519):1335-42.

[17] Carpenter CCJ, Fischl MA, and Hammer SM. Antiretroviral Therapy for HIV infection. JAMA 1996; 276:146-54. 